\title{
Influence of vitamin D serum concentration, prenatal care and social determinants on birth weight: a northeastern Brazilian cohort study
}

\author{
Marcos Pereira-Santos ${ }^{1,2 *}$, Gisele Queiroz Carvalho ${ }^{3}$, Djanilson Barbosa dos Santos ${ }^{4}$ and \\ Ana Marlucia Oliveira ${ }^{5}$ \\ ${ }^{1}$ Center of Biological and Health Sciences, Universidade Federal do Oeste da Babia, 47805-100 Barreiras, Brazil \\ ${ }^{2}$ Instituto de Saúde Coletiva, Universidade Federal da Babia, 40170-110 Salvador, Babia, Brazil \\ ${ }^{3}$ Department of Nutrition, Universidade Federal de Juiz de Fora, Campus Governador Valadares, 36036-900 Minas Gerais, Brazil \\ ${ }^{4}$ Center for Health Sciences, Universidade Federal do Recôncavo da Babia, 44574-490 Santo Antônio de Jesus, Babia, Brazil \\ ${ }^{5}$ School of Nutrition, Universidade Federal da Babia, 40170-110 Salvador, Babia, Brazil \\ (Submitted 22 July 2018 - Final revision received 29 March 2019 - Accepted 17 April 2019; First published online 11 June 2019)
}

\section{Abstract}

The relationship among social determinants, vitamin D serum concentration and the health and nutrition conditions is an important issue in the healthcare of pregnant women and newborns. Thus, the present study analyses how vitamin D, prenatal monitoring and social determinants are associated with birth weight. The cohort comprised 329 pregnant women, up to 34 weeks gestational age at the time of admission, who were receiving care through the prenatal services of Family Health Units. Structural equation modelling was used in the statistical analysis. The mean birth weight was 3340 (SD 0.545) g. Each nmol increase in maternal vitamin D serum concentration was associated with an increase in birth weight of $3.06 \mathrm{~g}$. Prenatal healthcare with fewer appointments $(\beta-41.49 \mathrm{~g}, 95 \% \mathrm{CI}-79.27,-3.71)$ and late onset of care in the second trimester or third trimester $(\beta-39 \cdot 24 \mathrm{~g}, 95 \% \mathrm{CI}-73 \cdot 31,-5 \cdot 16)$ favoured decreased birth weight. In addition, low socio-economic class and the practice of AfroBrazilian religions showed a direct association with high vitamin D serum concentrations and an indirect association with high birth weight, respectively. High gestational BMI ( $\beta 23 \cdot 84,95 \%$ CI 4.37, 43.31), maternal education level $(\beta 24.52 \mathrm{~g}, 95 \%$ CI $1 \cdot 82$, 47.23) and length of gestation ( $\beta$ 79.71, 95\% CI 52.81; 106.6) resulted in high birth weight. In conclusion, maternal vitamin D serum concentration, social determinants and prenatal care, evaluated in the context of primary healthcare, directly determined birth weight.

Key words: Vitamin D: Pregnant women: Primary healthcare: Social determinants of health

Epidemiological evidence indicates that social determinants and biological conditions are predictors of fetal development and health conditions as well as chronic non-communicable diseases in adult life ${ }^{(1)}$. Birth weight and prematurity are considered indicators of the overall health of the fetus and of the child ${ }^{(2)}$ and related to prenatal quality.

It is known that social inequities such as low income and maternal education level along with a lack of focus on health and social service policies are associated with morbidity and mortality in pregnant women and their children ${ }^{(3,4)}$. In the context of social inequalities, specific nutritional deficiencies may coexist $^{(5)}$, such as vitamin D deficiency (Fig. 1).

Vitamin D deficiency $(<50 \mathrm{nmol} / \mathrm{l})$ in pregnant women has been associated with compromised health during the gestational phase, which is reflected in the health of the fetus and newborn $^{(6)}$. Vitamin D deficiency is also associated with the occurrence of gestational diabetes, eclampsia and excessive weight gain among other morbidities during pregnancy, all of which have repercussions later in life for both mother and child $^{(7)}$. The association between poor concentrations of maternal vitamin $\mathrm{D}$ and the occurrence of low birth weight and prematurity has also been reported ${ }^{(7)}$. However, other studies did not find any associations between these events ${ }^{(8,9)}$.

Although the importance of micronutrients, particularly vitamin $\mathrm{D}$, and social determinants in the health of the population is recognised, epidemiological studies that adopt methodologies to analyse the direct link between these associations and determine the mediating factors, particularly in the reproductive life phase, are rare. Thus, the present study evaluates the relationship among maternal vitamin D serum concentration, prenatal monitoring, social determinants and birth weight.

Abbreviation: 25(OH)D, 25-hydroxyvitamin D.

* Corresponding author: Marcos Pereira-Santos, email pereira-santosm@bol.com.br 


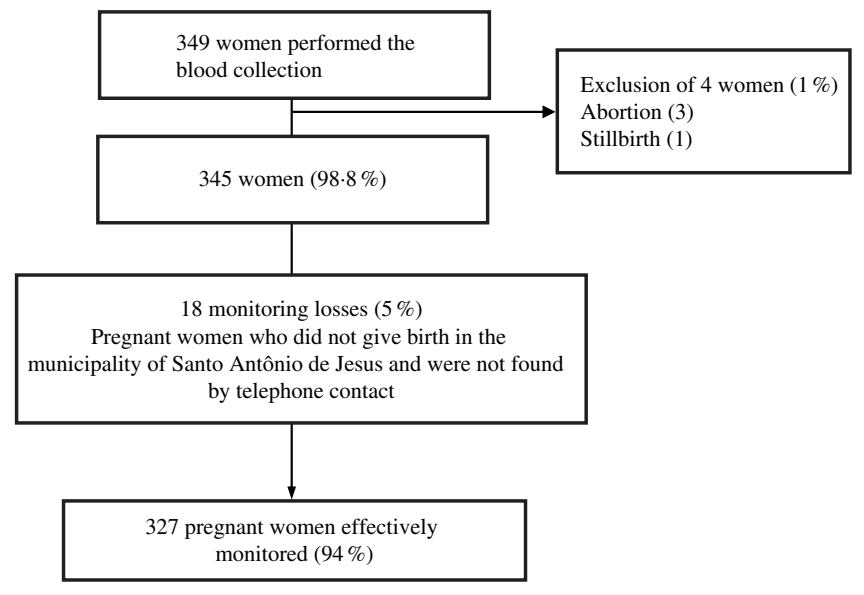

Fig. 1. Monitoring flowchart of pregnant women, 'Nutritional and genetic risk factors during pregnancy associated with low birth weight/prematurity. NISAMI cohort'. Santo Antônio de Jesus, Bahia, 2013-2015.

\section{Methods}

\section{Study design and sample}

This prospective, dynamic cohort study took place from June 2013 to September 2015, and included pregnant women who were receiving prenatal services from Family Health Units.

The study was conducted in the municipality of Santo Antônio de Jesus in the Recôncavo Sul Baiano; this municipality has an area of $261 \mathrm{~km}^{2}$ and is $187 \mathrm{~km}$ from the city of Salvador, the capital of the State of Bahia. Santo Antônio de Jesus has 90949 inhabitants, 79271 residents in urban areas and 116763 in rural areas, of which 47963 are women and 42986 men. In 2012, 874 children were born and 9.6\% had low birth weight $^{(10)}$. Santo Antônio de Jesus is located at $12^{\circ} 58^{\prime} \mathrm{S}$, $36^{\circ} 16^{\prime} \mathrm{W}$ and has a tropical climate (annual average of $23 \cdot 0^{\circ} \mathrm{C}$ ). Seasons of the year were defined as summer (DecemberJanuary-February), fall (March-April-May), winter (June-JulyAugust) and spring (September-October-November).

\section{Exclusion and inclusion criteria}

The study included women who lived in the urban area of the municipality, were at least over 18 years old, had gestational ages up to 34 weeks at the time of enrolment and received prenatal care from the Public Health System.

The criteria for exclusion after the baseline consisted of multiple gestations, pre-eclampsia, renal problems, HIV, abortion or fetal or embryonic death. Pregnant women previously enrolled who did not give birth in the medical units of the municipality and/or who could not be reached by telephone after delivery were excluded from the study.

Those women who met the following eligibility criteria ( $n$ 349) were referred to a clinical laboratory in the city and blood samples were collected after overnight fasting. Four women were excluded in addition to 18 women who did not give birth in the municipality of Santo Antônio de Jesus and were not located by telephone. After these exclusions, 327 pregnant women were effectively monitored (Fig. 1).

\section{Data collection and definition of variables}

After understanding the objectives of the investigation and the possible risks, the pregnant woman who consented to participate in the study signed the free informed consent form. After the agreement was signed, interviews about socio-economic, demographic and lifestyle characteristics were performed by trained interviewers and the information was recorded using a standardised questionnaire.

In the first stage of the cohort (baseline) when a pregnant woman was included in the study, the woman's pre-gestational weight was collected from the pregnancy chart. When not available, the weight provided by the woman was taken during the interview. Maternal height was measured by the health team at the clinic, who were trained according to the recommendations of Lohman et al. ${ }^{(11)}$. After these procedures, a date was scheduled for blood collection.

Gestational age was calculated based on the date of the last menstrual cycle, available on the pregnant woman's chart, or the gestational age was recorded from the first ultrasound, which was performed by the end of the first trimester.

Blood collection was performed between 7:00 and 9:00 a.m. after at least 8 hours of fasting at the Research Center in Maternal and Child Health of the municipality. After collection, the blood was centrifuged for $15 \mathrm{~min}$ at $2000 \mathrm{rpm}$ in an environment protected from ultraviolet light for serum separation. Serological samples were identified by codes and stored at $-32^{\circ} \mathrm{C}$ in a freezer until the serum concentration of 25-hydroxyvitamin D (25(OH)D) was measured. The dosage of vitamin $\mathrm{D}$ was performed with the quantitative determination method, based on the chemiluminescence principle (CLIA. A 25(OH)D dosing kit was used (DiaSorin ${ }^{\circledR}$ ), with an intra-assay CV of $8.4-12.5 \%$ and an intra-assay $\mathrm{CV}$ of $8 \cdot 6-11 \cdot 0 \%$.

Serum concentrations of $25(\mathrm{OH}) \mathrm{D}$ were classified as deficient $(<50 \mathrm{nmol} / \mathrm{l})$, insufficient $(50-75 \mathrm{nmol} / \mathrm{l})$ and sufficient $(>75 \mathrm{nmol} / \mathrm{l})^{(12)}$. A complete blood count and total Ca levels were also obtained. The haemogram was performed by fluorescence flow cytometry with a semiconductor laser (Sysmex XT $\left.1800 i^{\circledR}\right)$ and total Ca was measured by the Vitros dry chemical method (Johnson \& Johnson ${ }^{\circledR}$ ) in a reference laboratory of the municipality.

In the second step of the study between September 2013 and December 2015, the pregnant women were monitored until the birth of their child. The gestational weight gain was measured by the study team; in cases where information was missing, the data were collected from the pregnant woman's chart in the Family Health Units. The gestational weight gain was classified according to the maternal pre-gestational BMI, adopting the criteria of the Institute of Medicine ${ }^{(13)}$.

The birth weight was measured with the child naked using a digital paediatric scale, Welmy ${ }^{\circledR}$ brand, with a capacity of $15 \mathrm{~kg}$ and a $10 \mathrm{~g}$ interval. The anthropometric measurement was performed in duplicate and a maximum variation of $10 \mathrm{~g}$ for the weight was acceptable. When different values were obtained, a third measurement was performed. The final measurement was calculated as the mean of the values of the closest measurements ${ }^{(14)}$. 


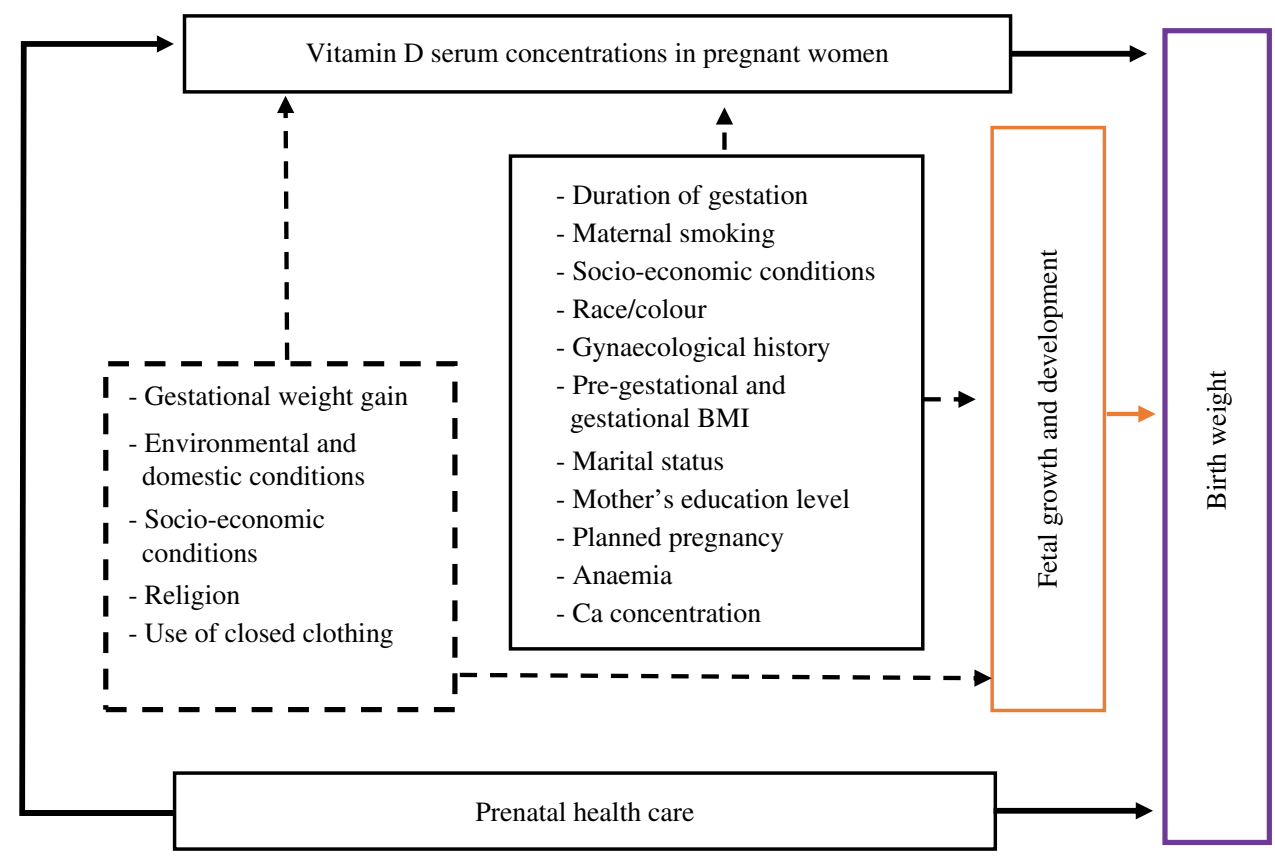

Fig. 2. Relationship between vitamin $D$ serum concentration, prenatal care and social determinants and birth weight.

Data related to the children's birth were collected from the Department of Epidemiological Monitoring (VIEP) of the Municipal Health Department. Home visits were performed at the end of the study for those pregnant women whose data on gestational outcomes were not found in the VIEP.

The $Z$ score of birth weight for gestational age was classified according to the sex of the newborn ${ }^{(15)}$. Birth weight was classified as small for gestational age (below the tenth percentile), appropriate for gestational age (tenth to ninetieth percentile) and large for gestational age (above the ninetieth percentile) ${ }^{(16)}$.

\section{Theoretical model}

The theoretical model of the study is presented in Fig. 2. The response variable (endogenous) of this model is observable and represented by the birth weight. It expresses a single event in the individual's life and is integrated into the regression model in a continuous form.

Exposure variables (exogenous) are observable and integrated by those that are directly associated with birth weight, according to references in the literature. They were included in a continuous form: maternal $25(\mathrm{OH}) \mathrm{D}$ concentration, total $\mathrm{Ca}, \mathrm{Hb}$, maternal education and age, family income, number of pregnancies, starting month of prenatal care, pregestational and gestational BMI, maternal weight gain, duration of gestation and number of consultations during pregnancy. The other items integrated into the model in the categorical form include: sex of the child (male (0), female (1)); skin colour (yellow, white, indigenous (0), brown (1), black (2)); smoker (yes (1), no (0)); alcohol consumer (yes (1), no (0)); marital status (living with partner (0), no partner (1)); planned pregnancy (yes (0), no (1)); and socio-economic class according to the Brazilian Association of Research Companies (ABEP), which considers the possession of goods (television, radio, car, washing machine, VCR or DVD, refrigerator and freezer), education level of the head of the family, number of toilets/bathrooms in the household and presence of a monthly maid, later categorised into A or B, C, D or E, respectively.

In addition to the exogenous variables, intermediate variables of the relationship between vitamin $\mathrm{D}$ serum concentration and birth weight were also selected based on those indicated in the literature, including the use of closed clothing $(\leq 1$ time per week (0), 2-4 times per week (1)); religion (Catholic (1), protestant (2), spiritism (3), Afro-Brazilian religions (4)); and season that the blood was collected (summer (0), spring (1), autumn (2), winter (3)).

\section{Statistical analyses}

Justification of sample size. The sample of the present study was calculated based on the equation for the cross-sectional mean test, an alternative that can be used when the longitudinal study response variable is a single event such as birth weight, as suggested by Twisk ${ }^{(17)}$. Mean serum vitamin D levels of $62.8(\mathrm{sD} 7.8) \mathrm{nmol} / \mathrm{l}$ were considered as the mean values for eutrophic pregnant women ${ }^{(18)}$, with $25 \%$ of concentrations ${ }^{(19)}$, mean weight at birth of $3196 \mathrm{~g}$, standard deviation of $56 \mathrm{~g}^{(14)}$ and type I error $(\alpha)$ of 5 and $80 \%$ of power $(1-\alpha)$. Thus, the sample size requirement was 149 women. Considering that during the study period it was possible to accompany 327 pregnant women, it was decided to include all of them in the sample to analyse the theoretical model with the path analysis.

\section{Descriptive analysis}

Prevalence was adopted to describe the categorical variables. Mean and standard deviation were used for the continuous variables. To characterise the study sample, the quantitative 
Table 1. Percentage distribution and mean $Z$ score of birth weight according to sociodemographic characteristics and biological variables of mothers and newborns, NISAMI cohort, Santo Antônio de Jesus, Bahia, Brazil, 2013-2015

\begin{tabular}{|c|c|c|c|c|c|}
\hline Variable & $n$ & $\%$ & $\begin{array}{c}\text { Mean } \\
Z \text { score of } \\
\text { birth weight }\end{array}$ & SD & $P$ \\
\hline \multicolumn{6}{|l|}{ Age (years), $n 324$} \\
\hline $18-24$ & 121 & 38 & 0.44 & $1 \cdot 13$ & \\
\hline $25-30$ & 91 & 28 & 0.44 & $1 \cdot 20$ & \\
\hline $31-35$ & 85 & 26 & 0.59 & $1 \cdot 10$ & \\
\hline $36-55$ & 27 & 8 & 0.83 & $1 \cdot 17$ & 0.34 \\
\hline \multicolumn{6}{|l|}{ Skin colour } \\
\hline White & 52 & 16 & 0.46 & $1 \cdot 21$ & \\
\hline Brown & 150 & 46 & 0.56 & $1 \cdot 15$ & \\
\hline Black & 125 & 38 & 0.47 & $1 \cdot 11$ & 0.55 \\
\hline \multicolumn{6}{|l|}{ Marital status } \\
\hline With partner & 272 & 83 & 0.48 & $1 \cdot 16$ & \\
\hline Without partner & 55 & 17 & 0.62 & 1.06 & 0.41 \\
\hline \multicolumn{6}{|c|}{ Maternal education, $n 324$} \\
\hline Up to 8 years & 61 & 19 & 0.47 & 1.29 & \\
\hline $9-12$ years & 220 & 68 & 0.56 & $1 \cdot 10$ & \\
\hline$>12-16$ years & 43 & 13 & 0.30 & $1 \cdot 18$ & 0.36 \\
\hline \multicolumn{6}{|l|}{ Maternal employment } \\
\hline With income & 161 & 49.85 & 0.52 & 1.22 & \\
\hline Without income & 166 & $50 \cdot 15$ & 0.49 & 1.08 & 0.82 \\
\hline \multicolumn{6}{|c|}{ Family income (minimum wages), $n 318$} \\
\hline$\leq 1$ & 50 & 16 & 0.51 & $1 \cdot 12$ & \\
\hline $1-3$ & 201 & 64 & 0.56 & $1 \cdot 15$ & \\
\hline $4-5$ & 27 & 12 & 0.52 & $1 \cdot 15$ & \\
\hline$>5$ & 40 & 8 & 0.25 & 1.17 & 0.48 \\
\hline \multicolumn{6}{|c|}{ Participation in social welfare programme } \\
\hline Yes & 87 & 27 & 0.514 & 1.09 & \\
\hline No & 240 & 73 & 0.512 & $1 \cdot 17$ & 0.98 \\
\hline \multicolumn{6}{|c|}{ Prenatal healthcare } \\
\hline \multicolumn{6}{|c|}{ Began prenatal healthcare } \\
\hline First month & 71 & 22 & 0.68 & 1.17 & \\
\hline Second month & 132 & 40 & 0.40 & 1.14 & \\
\hline Third month & 58 & 18 & 0.58 & $1 \cdot 12$ & \\
\hline Fourth or later & 66 & 20 & 0.48 & $1 \cdot 15$ & 0.38 \\
\hline \multicolumn{6}{|l|}{ Number of visits } \\
\hline$<6$ & 265 & 81 & 0.53 & $1 \cdot 17$ & \\
\hline$\geq 6$ & 62 & 19 & 0.43 & 1.07 & 0.56 \\
\hline \multicolumn{6}{|l|}{ Planned pregnancy } \\
\hline Yes & 121 & 37 & 0.45 & 1.20 & \\
\hline No & 206 & 63 & 0.54 & $1 \cdot 12$ & 0.48 \\
\hline \multicolumn{6}{|l|}{ Smoker } \\
\hline Yes & 22 & 7 & 0.71 & 1.01 & \\
\hline No & 305 & 93 & 0.49 & $1 \cdot 16$ & 0.40 \\
\hline \multicolumn{6}{|l|}{ Alcohol consumer } \\
\hline Yes & 31 & 9 & 0.27 & 1.05 & \\
\hline No & 296 & 91 & 0.53 & $1 \cdot 15$ & 0.22 \\
\hline \multicolumn{6}{|c|}{ Concentration of $25(\mathrm{OH}) \mathrm{D}$} \\
\hline$<50 \mathrm{nmol} / \mathrm{l}$ & 70 & 21 & $0 \cdot 10$ & 1.26 & \\
\hline$\geq 50-80 \mathrm{nmol} / \mathrm{l}$ & 147 & 45 & 0.56 & 1.09 & \\
\hline$>80 \mathrm{nmol} / \mathrm{l}$ & 110 & 34 & 0.69 & 1.09 & $<0.01$ \\
\hline \multicolumn{6}{|l|}{ Pre-gestational BMI } \\
\hline $18.5-24.9 \mathrm{~kg} / \mathrm{m}^{2}$ & 205 & 68 & 0.38 & $1 \cdot 11$ & \\
\hline$\geq 25.0 \mathrm{~kg} / \mathrm{m}^{2}$ & 122 & 32 & 0.72 & $1 \cdot 17$ & $<0.01$ \\
\hline \multicolumn{6}{|l|}{ Parity } \\
\hline 0 & 189 & 58 & 0.56 & $1 \cdot 13$ & \\
\hline$\geq 1$ & 138 & 42 & 0.44 & 1.17 & 0.33 \\
\hline
\end{tabular}

25(OH)D, 25-hydroxyvitamin D.

variables were categorised as shown in Table 1 . The mean $Z$ score according to the exposure variables was compared using Student's $t$ test for equal variances and ANOVA.

\section{Path analysis}

To evaluate the association between vitamin D serum concentration, prenatal care and social determinants and birth weight, modelling with path analysis was used. Adjustment of the theoretical model and observed values were evaluated through different tests. To evaluate the acceptance of the theoretical model, the Bentler's comparative fit index and the Tucker-Lewis index were used to analyse the adequacy of the theoretical model. In these indices, the results equal to 1 reflect a perfect fit, corresponding to the best fit of the model to the data ${ }^{(20)}$ and thus acceptance of the proposed theoretical model.

Data were analysed by the Stata software version 13 .

\section{Ethical considerations}

The study protocol was approved by the Research Ethics Committee of the School of Nutrition of the Universidade Federal da Bahia and the Faculdade Adventista da Bahia and conducted according to the guidelines laid down in the Declaration of Helsinki and Brazilian Resolution 466/2012. Informed consent was obtained from all individual participants included in the study.

\section{Results}

Of the 349 pregnant women, 327 (94\%) completed the monitoring required by the study. The mean vitamin D serum concentration did not differ between those who completed and those who did not complete the monitoring $(P=0 \cdot 81)$. The maternal and newborn characteristics are presented in Table 1 and include a mean age of 26.91 (SD 5.87) years, low income ( $80 \%$ ) and maternal education level between 8 and 11 years (69\%).

Pre-gestational BMI classified $32 \%$ of the pregnant women as overweight $\left(\geq 25 \mathrm{~kg} / \mathrm{m}^{2}\right)$ and $27.0 \%$ gained excessive weight during pregnancy. The mean total plasma Ca was 9.39 (SD 4.39) $\mathrm{mg} / \mathrm{l}$ and anaemia affected $20.0 \%$ of the mothers. Late starting of prenatal care was reported for $60 \%$ of the mothers.

Tables 2 and 3 present the structural modelling results obtained according to the proposed theoretical model (Fig. 2). The coefficients express the direct, indirect and total association of each variable on maternal vitamin D serum concentration and birth weight.

\section{Concentration of vitamin D in pregnant women}

The mean concentrations of $25(\mathrm{OH}) \mathrm{D}$ were $72 \cdot 29$ (SD 30.34) $\mathrm{nmol} / \mathrm{l}$. The percentages of insufficient and deficient serum concentrations of vitamin D were 45.0 and $21.0 \%$, respectively, totalling $66.0 \%$ of hypovitaminosis D. A direct association was found among low socio-economic class ( $\beta$ 6.19; $95 \% \mathrm{CI}$ $0.79,11.59 ; P=0.02)$, Afro-Brazilian religions $(\beta 2.82 ; 95 \% \mathrm{CI}$ $0.76,4.88 ; P=0.01$ ) and high vitamin $\mathrm{D}$ levels in pregnant women. However, during the winter period, decreased serum vitamin D 25(OH)D levels were observed at $-3.60(95 \% \mathrm{CI}$ $-6.84,0.35 ; P=0.03) \mathrm{nmol} / \mathrm{l}$. The use of closed clothing favoured a decrease of $-8.29(95 \%$ CI $-15.15,1.44 ; P=0.01)$ $\mathrm{nmol} / \mathrm{l}$ vitamin D serum concentration (Table 2 ). 
Table 2. Coefficients of path analysis, the relationship between prenatal care, social determinants and vitamin $D$ concentration in pregnant women ( $n$ 326), Santo Antônio de Jesus, Bahia, 2013-2015* ( $\beta$-Coefficients and $95 \%$ confidence intervals)

\begin{tabular}{lccr}
\hline & \multicolumn{3}{c}{ Direct and total effect } \\
\cline { 2 - 4 } Variables & \multicolumn{1}{c}{$\beta$} & $95 \% \mathrm{Cl}$ & \multicolumn{1}{c}{$P$} \\
\hline Age & 0.083 & $-0.53,0.70$ & 0.79 \\
Race/skin colour & 2.70 & $-7.06,1.65$ & 0.22 \\
Maternal education level & -0.92 & $-2.36,0.10$ & 0.20 \\
Family income & 0.008 & $-0.002,0.04$ & 0.48 \\
Marital status & -7.64 & $-16.01,0.72$ & 0.07 \\
Socio-economic class & 6.19 & $0.79,11.59$ & 0.02 \\
Social welfare & 1.70 & $-6.35,9.76$ & 0.67 \\
Maternal smoking & -15.37 & $-26.10,-4.64$ & $<0.01$ \\
Alcohol consumer & -5.67 & $-16.67,5.33$ & 0.31 \\
Age of menarche & 1.54 & $-0.51,3.60$ & 0.14 \\
Prenatal healthcare with & 1.17 & $-0.99,3.35$ & 0.28 \\
appointments (second & & & \\
trimester and third trimester) & & & \\
Gestational BMI & 0.28 & $-0.41,0.97$ & 0.42 \\
Pre-gestational BMI & 1.70 & $6.35,9.76$ & 0.67 \\
Gestational weight gain & -0.36 & $-0.93,0.21$ & 0.21 \\
Hb concentration & 1.84 & $-1.58,5.28$ & 0.29 \\
Ca concentration & 0.67 & $-0.04,1.38$ & 0.06 \\
Use of closed clothing & -8.29 & $-15.15,-1.44$ & 0.01 \\
Religion & 2.82 & $0.76,4.88$ & $<0.01$ \\
Winter season & -3.60 & $-6.84,-0.35$ & 0.03 \\
\hline
\end{tabular}

* Root mean square error of approximation: 000, comparative fit index: 1.0, TuckerLewis index: 1.0.

\section{Determinants of birth weight}

Caesarean delivery occurred in $66.26 \%$ of the births and $48.46 \%$ of the newborns were male. The mean birth weight was 3296.7 (SD 572.48) $\mathrm{g}$ and the prevalence of very low birth weight ( $<2500 \mathrm{~g}$ ) was $4.7 \%$, while the prevalence of low birth weight $(<3000 \mathrm{~g})$ was $17 \cdot 18 \%$. There was a high frequency of large for gestational age $(25 \%)$ and a low occurrence of small for gestational age $(5.0 \%)$. Of the pregnant women monitored, $8 \%$ gave birth to a newborn at less than 37 weeks gestation, and this was directly associated with birth weight $(P \leq 0 \cdot 01)$.

Vitamin D serum concentration had a direct and statistically significant association with birth weight. Each nmol increase in maternal vitamin D serum concentration correlated with an increase in birth weight of 3.06 (95\% CI $-1.37,4.75) \mathrm{g}$ $(P \leq 0.01)$ (Fig. 3).

Social determinants had a strong influence on birth weight (Table 3). An increase in maternal education level favoured a higher birth weight ( $\beta 24.52 \mathrm{~g} ; 95 \%$ CI 1.82, 47.23; $P=0.03$ ). Late onset of prenatal care was associated with a decrease in birth weight $(\beta-39 \cdot 24 \mathrm{~g}$; $95 \% \mathrm{CI}-73 \cdot 31,5 \cdot 16 ; P=002)$ when compared with women who started monitoring in the first months of gestation. Fewer consultations during pregnancy were also associated with a decrease in newborn weight $(\beta$ -41.49 g; $95 \%$ CI $-79 \cdot 27,3 \cdot 71 ; P=0.03)$.

In relation to maternal and obstetric characteristics, gestational BMI was associated with an increase in birth weight of $23.84 \mathrm{~g}$ for each unit increase $\left(\mathrm{kg} / \mathrm{m}^{2}\right)$ in BMI $(95 \%$ CI 4.37 , 43.31; $P=0 \cdot 01)$. Gestational age showed a strong association with birth weight. A 1-week increase in the duration of gestation favoured a gain of $79.71 \mathrm{~g}(95 \% \mathrm{CI} 52 \cdot 81,106 \cdot 6 ; P \leq 0 \cdot 01)$. The girls on average had a lower birth weight of $186 \mathrm{~g}$ than the boys (95\% CI $-283.40,-89.42 \mathrm{~g} ; P \leq 001)$.

Intervening variables with indirect associations influenced the relationship between maternal vitamin D serum concentration and birth weight, such as maternal smoking $(\beta-15.37 \mathrm{~g}$; $95 \%$ CI $-26 \cdot 10,4.64 ; P \leq 0 \cdot 01)$, the use of closed clothing during pregnancy $(\beta-8.29 ; 95 \%$ CI $-15.15,1.44 ; P=0.01)$ and the winter season $(\beta-3.60 ; 95 \% \mathrm{CI}-6 \cdot 8,0 \cdot 35 ; P=0.03)$, which all contributed to the lower birth weight. Low socioeconomic class was associated with a higher birth weight $(\beta 6.19 ; 95 \%$ CI $0.79,1.59 ; P=0.05)$ as was the practice of an Afro-Brazilian religion by the mother ( $\beta 2.82 ; 95 \% \mathrm{CI}$ $0 \cdot 76,4 \cdot 88 ; P \leq 0 \cdot 01)$.

The model presented an adequate fit index (comparative fit index $=1$; Tucker-Lewis index $=1$ ), indicating that it explains well the relationships tested in the present study.

\section{Discussion}

The results of the present study indicate that social determinants act directly on maternal vitamin D serum concentrations and birth weight. The number of consultations during pregnancy and the month of beginning prenatal care are direct determinants of birth weight. Vitamin D serum concentration also directly affects birth weight. Thus, biological determinants and social inequalities in healthcare directly affect maternal health conditions and, consequently, infant birth weight.

In general terms, the high occurrence of deficiency (21\%) and insufficiency ( $45 \%$ ) of vitamin D in pregnant women registered in the present study follow the trends reported in countries with cold climates, even though Brazil has a predominantly tropical climate. Due to the greater availability of ultraviolet rays in tropical countries such as Brazil, the population has an increased ability to generate photoproduction of vitamin D, which reduces deficiency of this vitamin ${ }^{(21)}$.

In pregnant women, an estimated $18-90 \%$ of vitamin D deficiency occurs in European countries, 66-96\% in Southeast Asia and $41-97 \%$ in the Pacific region ${ }^{(21)}$. Observational studies have registered a slightly lower occurrence of vitamin D insufficiency in pregnant women, ranging from $9 \cdot 3^{(22)}$ to $53 \%^{(23)}$. Studies show that deficiency and insufficiency are associated with low birth weight ${ }^{(7)}$. This is because vitamin $\mathrm{D}$ actively participates in the process of fetal growth and development.

The pregnant women in our study were not supplemented with vitamin $\mathrm{D}^{(24,25)}$. Furthermore, in Brazil, vitamin D intake through dietary sources is low and pregnant women who participate in public prenatal care programmes do not use vitamin D supplementation $^{(26,27)}$. In Brazil, only supplementation with Fe $(40 \mathrm{mg})$ and folic acid $(400 \mu \mathrm{g})$ is mandatory for pregnant women ${ }^{(27)}$.

In our study, the mean birth weight values $(3296 \cdot 7$ (sD 572.48) g) are higher than those found in pregnant women in neighbouring municipalities (3229.1 (sD 402.4) g) ${ }^{(14)}$. A study in Rio de Janeiro also registered a low value of mean birth weight $(3253 \mathrm{~g})^{(28)}$. Therefore, the results show that the mean birth weight of newborns reaches expected values under adequate conditions of fetal growth. 
Table 3. Coefficients of path analysis, the relationship between prenatal care, social determinants and vitamin D concentration in pregnant women on birth weight ( $n$ 326), Santo Antônio de Jesus, Bahia, 2013-2015

( $\beta$-Coefficients and $95 \%$ confidence intervals)

\begin{tabular}{|c|c|c|c|c|c|c|c|c|c|}
\hline \multirow[b]{2}{*}{ Variables } & \multicolumn{3}{|c|}{ Direct effect } & \multicolumn{3}{|c|}{ Indirect effect } & \multicolumn{3}{|c|}{ Total effect } \\
\hline & $\beta$ & $95 \% \mathrm{Cl}$ & $P$ & $\beta$ & $95 \% \mathrm{Cl}$ & $P$ & $\beta$ & $95 \% \mathrm{Cl}$ & $P$ \\
\hline $25(\mathrm{OH}) \mathrm{D}$ & 3.06 & $1.37,4.75$ & $<0.01$ & _- & _- & & 3.06 & $1.37,4.75$ & $<0.01$ \\
\hline Age & 3.70 & $-6.03,13.43$ & 0.45 & _- & _ & & 3.95 & $-5.96,13.87$ & 0.43 \\
\hline Race/colour & 13.43 & $-55.43,82.29$ & 0.80 & - & - & & $5 \cdot 13$ & $-4 \cdot 86,75 \cdot 13$ & 0.88 \\
\hline Mother's education level & 24.52 & $1 \cdot 82,47 \cdot 23$ & 0.03 & _- & - & & 21.73 & $-1 \cdot 19,44.66$ & 0.06 \\
\hline Family income & 0.00 & $-0.05,0.05$ & 0.97 & - & - & & 0.01 & $-0.051,0.0548$ & 0.95 \\
\hline Marital status & $101 \cdot 23$ & $-32,234 \cdot 70$ & 0.13 & - & - & & $77 \cdot 78$ & $-57.39,212.96$ & 0.25 \\
\hline Socio-economic class & 52.93 & $-31.83,137.70$ & 0.22 & $\overline{6} \cdot 19$ & $0.79,11.59$ & 0.05 & 71.94 & $-13 \cdot 4,157.35$ & 0.09 \\
\hline Social welfare & -118.97 & $-245 \cdot 46,7.50$ & 0.06 & - & & & -113.74 & $-242,15 \cdot 12$ & 0.08 \\
\hline Maternal smoking & -20.61 & $-193.83,46.35$ & 0.81 & $-15 \cdot 37$ & $-26 \cdot 10,-4 \cdot 64$ & 0.00 & -70.89 & $-242 \cdot 63,100 \cdot 84$ & 0.41 \\
\hline Number of residents & -2.88 & $-38 \cdot 10,32 \cdot 33$ & 0.87 & _ & - & & $-127 \cdot 36$ & $-302 \cdot 18,47 \cdot 46$ & 0.15 \\
\hline Alcohol consumer & -109.96 & $281 \cdot 65,61 \cdot 72$ & 0.20 & - & - & & $7 \cdot 22$ & $-4.32,18 \cdot 77$ & 0.22 \\
\hline Age of menarche & $25 \cdot 63$ & $-6 \cdot 95,58 \cdot 22$ & 0.12 & - & - & & $30 \cdot 36$ & $-2 \cdot 72,63 \cdot 4$ & 0.07 \\
\hline Number of pregnancies & 27.45 & $24.27,79 \cdot 19$ & 0.29 & - & - & & 24.50 & $-28 \cdot 16,77 \cdot 17$ & 0.36 \\
\hline Planned pregnancy & 34.35 & $-69.47,138.17$ & 0.51 & - & - & & 30.99 & $-71.80,133$ & 0.55 \\
\hline $\begin{array}{l}\text { Prenatal healthcare with } \\
\text { less appointments (second } \\
\text { trimester and third trimester) }\end{array}$ & $-39 \cdot 24$ & $-73 \cdot 31,-5 \cdot 16$ & 0.02 & - & - & & $-35 \cdot 63$ & $-70 \cdot 30,-0.95$ & 0.04 \\
\hline $\begin{array}{l}\text { Number of consultations } \\
\text { during pregnancy }\end{array}$ & -41.49 & $-79 \cdot 27,-3 \cdot 71$ & 0.03 & - & - & & -41.49 & $-79 \cdot 27,-3 \cdot 71$ & 0.03 \\
\hline Sex of the child, female & -186 & $-283.40,-89.42$ & $<0.01$ & _- & _- & & -186 & $-283.40,-89.42$ & $<0.01$ \\
\hline Duration of gestation & 79.71 & $52 \cdot 81,106 \cdot 6$ & $<0.01$ & - & - & & 79.71 & $52 \cdot 8,106 \cdot 61$ & $<0.01$ \\
\hline Gestational BMI & 23.84 & $4 \cdot 37,43 \cdot 31$ & 0.01 & - & - & & 23.84 & $4.372,43.31$ & 0.01 \\
\hline Pre-gestational BMI & 4.86 & $-14 \cdot 76,24 \cdot 49$ & 0.62 & - & - & & 4.86 & $-14 \cdot 76,24.49$ & 0.62 \\
\hline Gestational weight gain & 8.34 & $-3.06,19.75$ & 0.16 & - & - & & $7 \cdot 22$ & $-4.32,18.77$ & 0.22 \\
\hline $\mathrm{Hb}$ concentration & -13.46 & $-67.44,40.51$ & 0.62 & - & - & & -7.80 & $-62 \cdot 79,47 \cdot 18$ & 0.78 \\
\hline Ca concentration & 3.86 & $-7 \cdot 45,15 \cdot 16$ & 0.50 & - & $\begin{array}{l}- \\
-\end{array}$ & & 5.92 & $-5 \cdot 50,17.35$ & 0.31 \\
\hline Use of closed clothing & - & - & & -8.29 & $-15 \cdot 1 \overline{5}, 1 \cdot 44$ & $\leq 0.01$ & $-25 \cdot 44$ & $-50.70,-0.191$ & 0.04 \\
\hline Religion & - & - & & 2.82 & $0.76,4.88$ & $\leq 0.01$ & 8.66 & $0.75,16.58$ & 0.03 \\
\hline Winter season & _- & _- & & $-3 \cdot 60$ & $-6 \cdot 8,-0.35$ & 0.03 & 11.04 & $-22 \cdot 7,0 \cdot 61$ & 0.06 \\
\hline
\end{tabular}

25(OH)D, 25-hydroxyvitamin D.

* Root mean square error of approximation: 000, comparative fit index: $1 \cdot 0$, Tucker-Lewis index: 1.0. 

Fitted values; $\quad, 95 \% \mathrm{Cl}$.

The analytical challenge of understanding the relationship between social determinants, vitamin D serum concentrations and birth weight is to establish a hierarchy of determinants among macrosocial factors and to identify how these factors impact individual and group health mainly by understanding that relationship is not causal. This perspective can be modelled with path analysis or a path diagram.

In this context, maternal education and low socio-economic status were directly related to maternal vitamin D serum concentration and birth weight. The maternal education level is indicated as decisive in influencing health conditions in childhood, especially in gestational outcomes ${ }^{(28)}$. This condition extends to the protection of newborns from prematurity, low birth weight and respiratory complications ${ }^{(29)}$. However, low socio-economic level was associated with an increase in vitamin D serum concentration and fetal weight gain. This could be due to issues related to work situations, such as being subject to underemployment and to working in hostile conditions associated with high sun exposure and little access to long clothing and protective sunblock.

Although climate is a key factor in the photoproduction of vitamin $\mathrm{D}$, studies have observed a positive association between vitamin D deficiency and low socio-economic status in countries with a cold climate ${ }^{(30)}$. Aspects of habits and lifestyle, which include diets with low dietary and supplemental sources of vitamin $\mathrm{D}$, impact the health of this population ${ }^{(31,32)}$.

Other records of the relationship between the socioeconomic class of pregnant women and higher birth weight have also been considered ${ }^{(2)}$. In the context of social inequality, eating habits can manifest in the consumption of high-calorie foods ${ }^{(2,33)}$. This may lead to excessive weight gain during the gestational phase and therefore the birth of heavier children.

Another fundamentally important aspect for good gestational development and women's health is the prenatal care provided by the Family Health teams. The mothers who started prenatal care in the first months of gestation and had more consultations during pregnancy delivered heavier babies. Prenatal care reduces prematurity and neonatal mortality. Maternal healthcare reduces complication rates during pregnancy and at delivery ${ }^{(34)}$.

The maternal and obstetric characteristics of pre-gestational BMI and duration of gestation are important. Gestational BMI directly impacted birth weight. Excess weight at the start of gestation is an important determinant of excessive weight gain during pregnancy. This explains the large number of children born who are classified as large for gestational age in the present study. For each increase of $1 \mathrm{~kg}$ in weight gain during pregnancy, there is an increase from 16.7 to $22.6 \mathrm{~g}$ in birth weight ${ }^{(13)}$. Children of women who had excessive weight gain are predisposed to being born with more body fat ${ }^{(35,36)}$ and to having a greater risk of developing obesity and chronic diseases during childhood and adulthood ${ }^{(1)}$.

It is also noteworthy that pregnant women involved in AfroBrazilian religions had increased vitamin D serum concentrations and showed an indirect association with increasing birth weight. An explanation for these results could be that the women who feed pregnant women practising Afro-Brazilian religions may provide a greater content of liposoluble vitamins and antioxidant compounds derived from palm oil ${ }^{(37)}$, which may indirectly contribute to better absorption of vitamin $\mathrm{D}$ from the diet and consequently higher birth weight. The result related to this aspect requires more study on the identified association, considering that the epidemiological literature does not report studies on gestational outcomes in women who practise Afro-Brazilian religions.

Cigarette smoking during pregnancy was associated with a low serum concentration of vitamin $\mathrm{D}$, and smokers gave birth to lighter weight children. The chemical substances in tobacco can compromise the hepatic metabolism of vitamin D and fetal 
development ${ }^{(38)}$. A meta-analysis found that the implementation of policies aimed at controlling smoking was associated with significant reductions in the rates of preterm birth ${ }^{(39)}$.

The present study has some limitations. We did not analyse the impact of haemodilution on the concentrations of $25(\mathrm{OH}) \mathrm{D}$ during pregnancy. In our cohort, there are many different gestational ages, and vitamin D binding protein (VDBP) changes throughout pregnancy should be considered ${ }^{(40)}$. VDBP is the major carrier of vitamin $\mathrm{D}$ and its derivatives and can be used in the diagnosis of vitamin D status during pregnancy. Therefore, we recommend that future studies consider this variable.

Another limitation of the present study is the lack of evaluation of the influence of food consumption and physical activity level on birth weight. Likewise, we do not have information about vitamin D metabolite concentrations in umbilical cord blood serum. Thus, our results may be confounded when those data are missing. However, this aspect did not affect the achievement of adjustments of the theoretical model considered excellent to evaluate the relationships between serum concentrations of vitamin $\mathrm{D}$, birth weight and mediating factors.

The longitudinal data and the robust statistical analysis in our study are additional strengths. In addition, we examined both the overall predicted status of vitamin D and the influence of maternal vitamin $\mathrm{D}$ serum concentration on birth weight.

To our knowledge, the present study is the first in Brazil to address the relationship among vitamin D serum concentration, social determinants and birth weight. The results of the present investigation indicate that the maternal serum concentration of vitamin D, the social determinants and the prenatal care carried out in the Primary Healthcare Units determined the birth weight. The present study indicates that prenatal care performed by Family Health Units is important to prevent nutritional disorders and to promote the health of women and children.

\section{Acknowledgements}

The authors thank all participants, principal investigators and collaborators of the NISAMI study.

The present study has been supported by the Brazilian National Research Council (CNPQ - project nos. 481509/ 2012-7: Factors of nutritional and genetic risk during pregnancy associated with low birth weight/prematurity).

M. P.-S. was involved in the project conception, development of the overall research plan, study oversight and analysed the data and wrote the paper. G. Q. C. was involved in the development of the overall research plan and with the writing of the manuscript. D. B. d. S. contributed to the project conception, supervised the study and drafted the manuscript. A. M. O. supervised the study and contributed to the design, statistical analyses, data interpretation and manuscript drafting. All authors approved the final manuscript for submission.

All authors declare no potential personal or financial conflicts of interest.

\section{References}

1. Barker DJP (2004) Developmental origins of adult health and disease. J Epidemiol Community Health 58, 114-115.
2. Coelho N de LP, Cunha DB, Esteves APP, et al. (2015) Dietary patterns in pregnancy and birth weight. Rev Saude Publica 49, 62 .

3. Wehby GL \& López-Camelo JS (2017) Maternal education gradients in infant health in four South American countries. Matern Child Health J 21, 2122-2131.

4. Rasella D, Aquino R, Santos CAT, et al. (2013) Effect of a conditional cash transfer programme on childhood mortality: a nationwide analysis of Brazilian municipalities. Lancet $\mathbf{3 8 2}$, $57-64$.

5. Assis AMO, Barreto ML, Santos NS, et al. (2007) Desigualdade, pobreza e condições de saúde e nutrição na infância no Nordeste brasileiro. Cad Saude Publica 23, 2337-2350.

6. Leffelaar ER, Vrijkotte TGM \& van Eijsden M (2010) Maternal early pregnancy vitamin $\mathrm{D}$ status in relation to fetal and neonatal growth: results of the multi-ethnic Amsterdam born children and their development cohort. Br J Nutr 104, 108-117.

7. Aghajafari F, Nagulesapillai T, Ronksley PE, et al. (2013) Association between maternal serum 25-hydroxyvitamin D level and pregnancy and neonatal outcomes: systematic review and meta-analysis of observational studies. BMJ 346, f1169-f1169.

8. Javaid MK, Crozier SR, Harvey NC, et al. (2006) Maternal vitamin D status during pregnancy and childhood bone mass at age 9 years: a longitudinal study. Lancet 367, 36-43.

9. Viljakainen HT, Saarnio E, Hytinantti T, et al. (2010) Maternal vitamin $\mathrm{D}$ status determines bone variables in the newborn. J Clin Endocrinol Metab 95, 1749-1757.

10. TabNet Win32 3.0: Sistema de Informação de Atenção Básica Situação de Saúde - Bahia [Internet]. http://tabnet.datasus .gov.br/cgi/deftohtm.exe?siab/cnv/SIABSba.def (accessed December 2017).

11. Lohman TG, Roche AF \& Martorell R (1988) Anthropometric Standardization Reference Manual. Champaign, IL: Human Kinetics Books.

12. Holick MF, Binkley NC, Bischoff-Ferrari HA, et al. (2011) Evaluation, treatment, and prevention of vitamin D deficiency: an endocrine society clinical practice guideline. J Clin Endocrinol Metab 96, 1911-1930.

13. Institute of Medicine (2009) Weight Gain During Pregnancy. Washington, DC: Institute of Medicine of the National Academies.

14. Queiroz VAO, Assis AMO \& Pinheiro SMC (2012) Predictors of linear growth in the first year of life of a prospective cohort of full term children with normal birth weight. J Pediat 89, 79-86.

15. Brasil (2011) Orientações para a coleta e análise de dados antropométricos em serviços de saúde (Guidance for the Collection and Analysis of Anthropometric Data Variables in Health Services). Brasilia: Ministério da Saúde Secr Atenção à Saúde Dep Atenção Básica.

16. Villar J, Cheikh Ismail L, Victora CG, et al. (2014) International standards for newborn weight, length, and head circumference by gestational age and sex: the Newborn Cross-Sectional Study of the INTERGROWTH-21st Project. Lancet 384, 857868.

17. Twisk JWR (2003) Applied Longitudinal Data Analysis for Epidemiology. Cambridge: Cambridge University Press.

18. Bodnar LM, Catov JM, Roberts JM, et al. (2007) Prepregnancy obesity predicts poor vitamin D status in mothers and their neonates. J Nutr 137, 2437-2442.

19. Kovacs CS (2011) Fetus, neonate and infant. In Vitamin D, 3rd ed., pp. 625-646 [D Feldman, WJ Pike and JS Adams, editors]. New York: Academic.

20. Amorim LDAF, Fiaccone RL, Santos CAST, et al. (2010) Structural equation modeling in epidemiology. Cad Saude Publica 26, 2251-2262. 
21. Saraf R, Morton SMB, Camargo CA \& Grant CC. (2016) Global summary of maternal and newborn vitamin D status - a systematic review. Matern Child Nutr 12, 647-668.

22. Karras S, Paschou SA, Kandaraki E, et al. (2016) Hypovitaminosis $\mathrm{D}$ in pregnancy in the Mediterranean region: a systematic review. Eur I Clin Nutr 70, 979-986.

23. Bowyer L, Catling-Paull C, Diamond T, et al. (2009). Vitamin D, PTH and calcium levels in pregnant women and their neonates. Clin Endocrinol (Oxf) 70, 372-377.

24. Costa DB, Coelho HLL \& Santos DB (2017) Utilização de medicamentos antes e durante a gestação: prevalência e fatores associados (Use of drugs before and during pregnancy: prevalence and associated factors). Cadernos de Saúde Pública 33 , e00126215.

25. Farias DR, Poston L, Franco-Sena AB, et al. (2017) Maternal lipids and leptin concentrations are associated with largefor-gestational-age births: a prospective cohort study. Sci Rep 7, 1

26. Pereira-Santos M, Santos JYGD, Carvalho GQ, et al. (2018) Epidemiology of vitamin D insufficiency and deficiency in a population in a sunny country: geospatial meta-analysis in Brazil. Crit Rev Food Sci Nutr (epublication ahead of print version 8 February 2018).

27. Benaim C, Cocate PG, de Barros EG, et al. (2019) Longitudinal association of 25-hydroxyvitamin D with adipokines and markers of glucose metabolism among Brazilian pregnant women. Br J Nutr 121, 42-54.

28. Fonseca NS (2012) Efeito da suplementação materna com vitamina A no puerpério sobre o estado de saúde e nutrição em crianças: um estudo de coorte (Effect of maternal supplementation with vitamin A in the puerperium on health status and nutrition in children: a cohort study). PhD Thesis, Universidade federal da Bahia: Programa de Pós-Graduação em Saúde Coletiva. Salavador, Bahia.

29. Marchi J, Berg M, Dencker A, Olander EK \& Begley C (2015). Risks associated with obesity in pregnancy, for the mother and baby: a systematic review of reviews. Obes Rev 16, 621-638.
30. Wang Y, Mao J, Wang W, et al. (2017) Maternal fat free mass during pregnancy is associated with birth weight. Reprod Health 14, 47.

31. Cantarutti A, Franchi M, Monzio Compagnoni M, et al. (2017) Mother's education and the risk of several neonatal outcomes: an evidence from an Italian population-based study. BMC Pregnancy Childbirth 17, 221.

32. Rodriguez A, Santa Marina L, Jimenez AM, et al. (2016) Vitamin D status in pregnancy and determinants in a Southern European cohort study. Paediatr Perinat Epidemiol 30, 217-228.

33. Santana JM, Queiroz VAO, Brito SM, et al. (2015) Food consumption patterns during pregnancy: a longitudinal study in a region of the North East of Brazil. Nutr Hosp 32, 130-138.

34. Anjos JC dos \& Boing AF (2016) Diferenças regionais e fatores associados ao número de consultas de pré-natal no Brasil: análise do Sistema de Informações sobre Nascidos Vivos em 2013 (Regional differences and factors associated with the number of prenatal consultations in Brazil: analysis of the Information System on Live Births in 2013). Rev Bras Epidemiol 19, 835-850.

35. Marchi J, Berg M, Dencker A, et al. (2015) Risks associated with obesity in pregnancy, for the mother and baby: a systematic review of reviews. Obes Rev 16, 621-638.

36. Wang Y, Mao J, Wang W, et al. (2017) Maternal fat free mass during pregnancy is associated with birth weight. Reprod Health 14, 47.

37. Sundram K, Sambanthamurthi R \& Tan YA (2003) Palm fruit chemistry and nutrition. Asia Pac J Clin Nutr 12, 355-362.

38. Van Den Berg G, Van Eijsden M, Vrijkotte TGM, et al. (2013) Suboptimal maternal vitamin D status and low education level as determinants of small-for-gestational-age birth weight. Eur J Nutr 52, 273-279.

39. Faber T, Kumar A, Mackenbach JP, et al. (2017) Articles association of tobacco control policies on perinatal and child health: a systematic review and meta-analysis. Lancet Public Health $\mathbf{2}$, e420-e443.

40. Zhang JY, Lucey AJ, Horgan R, et al. (2014) Impact of pregnancy on vitamin D status: a longitudinal study. Br J Nutr 112, 1081-1087. 